\title{
PCR Multiplex para detecção dos principais herpesvírus neurológicos de ruminantes
}

\author{
[Multiplex PCR for detection of Suid herpesvirus 1, Bovine herpesvirus 1, Bovine herpesvirus5, \\ Ovine herpesvirus 2] \\ A.A. Fonseca Jr. ${ }^{1}$, E.A. Costa ${ }^{2}$, T.S. Oliveira ${ }^{2,3}$, E.B. Sales ${ }^{1}$, M.L. Sales ${ }^{1}$, R.C. Leite ${ }^{2}$, \\ M. B.Heneimann ${ }^{2}$, J.K.P. Reis ${ }^{2}$ \\ ${ }^{1}$ Laboratório de Biologia Molecular - LANAGRO/MG - Pedro Leopoldo, MG \\ ${ }^{2}$ Escola de Veterinária - Universidade Federal de Minas Gerais - Belo Horizonte, MG \\ ${ }^{3}$ Instituto Mineiro de Agropecuária - Belo Horizonte, MG
}

\begin{abstract}
RESUMO
Desenvolveu-se uma PCR multiplex (mPCR) para diagnóstico diferencial de encefalite bovina causada por herpesvírus suíno 1 (SuHV-1), herpesvírus bovino 1 (BoHV-1), herpesvírus bovino 5 (BoHV-5) e herpesvírus ovino 2 (OvHV-2). Os iniciadores foram projetados após alinhamento de sequências disponíveis no banco de genomas (GenBank) e a reação foi padronizada levando-se em consideração a concentração dos reagentes e os tipos diferentes de DNA polimerase. Após determinação da especificidade e sensibilidade, 65 amostras de encéfalo de bovinos com síndrome neurológica foram submetidas à análise. A sensibilidade analítica para detecção de BoHV-1, BoHV-5 e SuHV-1 foi, respectivamente, $10^{1,2} \mathrm{TCID}_{50} / 50 \mu \mathrm{L}, 10^{1,0} \mathrm{TCID}_{50} / 50 \mu \mathrm{L}, 10^{1,3} \mathrm{TCID}_{50} / 50 \mu \mathrm{L}$ na reação multiplex. Das 65 amostras analisadas, 10 foram positivas para BoHV-5, uma para BoHV-1 e cinco para OvHV-2. A mPCR descrita neste trabalho mostrou-se uma técnica útil para o diagnóstico diferencial de enfermidades relacionadas ao sistema nervoso central de bovinos.
\end{abstract}

Palavras-chave: PCR, encefalite, herpesvírus

\begin{abstract}
The aim of this study was to develop a multiplex PCR (mPCR) for the differential diagnosis of bovine encephalitis caused by the suid herpesvirus 1 (SuHV-1), bovine herpesvirus 1 (BoHV-1), bovine herpesvirus 5 (BoHV-5) and ovine herpesvirus $2(\mathrm{OvHV}-2)$. The primers were designed after alignment of sequences available in GenBank and the reaction was developed by taking into account the concentration of reagents and different types of DNA polymerase. After determining the specificity and sensitivity to PCR, 65 brain samples from cattle with neurological syndrome were submitted to the reaction. The analytical sensitivity for detection of $\mathrm{BoHV}-1, \mathrm{BoHV}-5$ and $\mathrm{SuHV}-1$ was, respectively, $10^{1,2}$ $T_{C I D_{50}} / 50 \mu \mathrm{L}, 10^{1,0} \mathrm{TCID}_{50} / 50 \mu \mathrm{L}, 10^{1,3} \mathrm{TCID}_{50} / 50 \mu \mathrm{L}$. Ten samples were positive for BoHV-5, one for BoHV-1, one for SuHV-1 and five for $O v H V-2$. The mPCR described here is a useful technique for the differential diagnosis of diseases related to the central nervous system of cattle.
\end{abstract}

Keywords: PCR, encephalitis, herpesvirus

\section{INTRODUÇÃOO}

As doenças do sistema nervoso central dos bovinos podem ser provocadas por diversos agentes, alguns deles associados a zoonoses como o vírus da raiva e o agente da encefalopatia espongiforme bovina e outros com impacto exclusivo na saúde animal como os vírus da família Herpesviridae: herpesvírus bovino 1 (BoHV-1), herpesvírus bovino 5 (BoHV-5), herpesvírus ovino 2 (OvHV-2) e herpesvírus suídeo 1 (SuHV-1), capazes de causar sinais neurológicos que podem confundir o diagnóstico clínico (Claus et al., 2002). A partir das amostras 
de encéfalo, é possível realizar o diagnóstico diferencial destes agentes que afetam o sistema nervoso dos bovinos, além dos analisados no Programa Nacional de Controle da Raiva dos Herbívoros e Outras Encefalopatias do Ministério da Agricultura, Pecuária e Abastecimento (MAPA).

O BoHV-5 e o BoHV-1 são herpesvírus pertencentes à mesma subfamília Alphaherpesvirinae, gênero Varicellovírus (Davison et al., 2009). Esses dois vírus possuem identidade proteica de até $82 \%$, o que dificulta diferenciá-los tanto por métodos moleculares quanto sorológicos (Thiry et al., 2006). O BoHV-5 é agente etiológico da meningoencefalite bovina, uma enfermidade de curso rápido e geralmente fatal. Animais mais novos são mais suscetíveis, enquanto nos bovinos adultos, a gravidade da infecção depende muito da cepa viral e do status imunológico do hospedeiro (Rissi et al., 2007). Mundialmente, as ocorrências de infecção por BoHV-5 são mais comuns na América do Sul (Del Médico et al., 2010), sendo um dos principais agentes de encefalopatias bovinas no Brasil (Rissi et al., 2010).

O BoHV-1 é agente da rinotraqueíte infecciosa bovina, vulvovaginite e balanopostite pustular infecciosa, além de mortalidade neonatal devido à infecção sistêmica ou abortos, principalmente quando a infecção ocorre em vacas soronegativas (Muylkens et al., 2007). O BoHV-1 pode causar danos neurológicos, ainda que esse não seja um fenômeno comum (Brower et al., 2008; Rissi et al., 2008). Essa ocorrência rara foi demonstrada em dois estudos que trabalharam com diagnóstico molecular por PCR. O primeiro, realizado com amostras parafinadas coletadas ao longo de 10 anos no centro oeste brasileiro, não detectou o BoHV-1 em nenhum dos tecidos analisados (Arruda et al., 2010). O segundo estudo, realizado por Batista et al. (2010), diagnosticou apenas duas amostras positivas para BoHV-1 em sua forma infecciosa após análise de setenta amostras de encéfalos bovinos coletados no Rio Grande do Sul.

O SuHV-1, vírus pertencente à mesma subfamília e gênero dos vírus BoHV-5 e BoHV1, é o agente etiológico da pseudorraiva ou doença de Aujeszky (Braga et al., 2005). Os suínos são os principais hospedeiros do SuHV-1.
Este causa danos neurológicos em animais mais jovens e sinais respiratórios em indivíduos adultos. Espécies como cães, gatos e bovinos também são suscetíveis à infecção e apresentam uma encefalite de curso agudo fatal que pode ser confundida com os sinais causados pela infecção com o vírus da raiva (Pomeranz et al., 2005).

A febre catarral maligna (FCM) é uma enfermidade de bovinos e outros ungulados, como suínos, búfalos, bisões e cervos, caracterizada por sinais neurológicos, inapetência, febre e corrimento nasal (Garmatz et al., 2004; Costa et al., 2009). Os principais herpesvírus associados à enfermidade pertencem ao gênero Gammaherpesvírus, sendo considerados membros do grupo de vírus associados à FCM (Li et al., 2005). Dentre esses, o OvHV-2 é o principal causador da FCM em bovinos no Brasil, principalmente quando ocorre criação concomitante com ovinos (Riet-Correa $e t$ al., 1998). A enfermidade já foi diagnosticada na Europa, Oriente Médio, África e América do Sul (Russell et al., 2009).

Os quatro agentes citados podem ser diagnosticados por uma variedade de métodos, incluindo técnicas moleculares como a reação em cadeia pela polimerase (PCR). A PCR é um método rápido e sensível já utilizado para diagnóstico de várias enfermidades virais. A utilização de uma metodologia multiplex agiliza o processo de identificação desses agentes infecciosos por realizar o diagnóstico completo com apenas uma reação, além de ser menos onerosa (Yeh et al., 2009).

O objetivo deste trabalho foi desenvolver uma PCR multiplex (mPCR) para diagnóstico diferencial das encefalopatias dos bovinos.

\section{MATERIAL E MÉTODOS}

A padronização da PCR foi realizada com a amostra padrão Shope de SuHV-1 (ATCC VR135), amostra-padrão Colorado-1 de BoHV-1 (ATCC VR-864) e isolado EVI88/95 de BoHV-5 (Esteves et al., 2008). Devido à dificuldade de isolar o OvHV-2 (Gailbreath et al., 2008), o DNA extraído de leucócitos de uma ovelha naturalmente infectada pelo OvHV-2 foi utilizado como padrão nessa etapa do trabalho (Costa et al., 2009). 
Foram utilizadas 65 amostras de encéfalo de bovinos com sinais neurológicos e negativas para raiva por meio de técnicas de imunofluorescência direta (IFD) e inoculação intracerebral em camundongos (ICC), oriundas de várias regiões do estado de Minas Gerais, Brasil. As amostras foram cedidas pelo Instituto Mineiro de Agropecuária (IMA) após extração do DNA. A viabilidade do DNA foi avaliada por PCR para detecção do gene da $\beta$-actina bovina antes do envio para o Laboratório Nacional Agropecuário de Minas Gerais.

Além das amostras de tecido bovino, tecido animal proveniente de outras espécies suscetíveis a alguns vírus estudados nesse trabalho foi submetido à mPCR. Trinta e cinco amostras de encéfalo suíno caracterizadas em outro trabalho (Fonseca Jr. et al., 2010a) foram selecionadas. Vinte e cinco delas foram diagnosticadas como positivas para SuHV-1 por isolamento viral e PCR, e as 10 restantes tiveram resultados negativos nos mesmos testes. Da mesma forma, amostras de tecido ovino caracterizadas por PCR por Costa et al. (2007) também foram adicionadas neste trabalho. Quatro dessas provinham de encéfalo ovino, sendo três positivas e uma negativa para OvHV-2. Dez amostras provinham de sêmen ovino, sendo sete positivas e três negativas para OvHV-2.
O DNA das amostras foi extraído por métodos diferentes de acordo com a origem. As amostras derivadas de bovinos e ovinos, incluindo encéfalos e sêmen, foram extraídas pelo método da sílica previamente descrito por Boom et al. (1990). As amostras de encéfalo de suíno foram submetidas à extração de DNA conforme Fonseca Jr. (2010b).

Os iniciadores para a mPCR foram construídos no programa Primer3 Plus (http://www. bioinformatics.nl/cgi-bin/primer3plus/

primer3plus.cgi) após alinhamento no programa Bioedit das seguintes sequências disponíveis no banco de genomas GenBank (Hall, 1999; Untergasser et al., 2007). Os iniciadores foram submetidos a análises in silico de especificidade e formação de dímeros individualmente, em pares e em conjunto nos programas Blast (Altschul et al., 1990), PrimerBlast e OligoCalc (Kibbe, 2007). Os critérios de seleção foram temperaturas de fusão semelhantes, alta especificidade e número mínimo de interações. Três pares de iniciadores (Tab. 1) foram selecionados, sendo o iniciador BoHV 191 capaz de detectar o DNA de ambos BoHV-1 e BoHV-5.

Tabela 1. Lista de oligonucleotídeos iniciadores utilizados para detecção de DNA dos herpesvírus BoHV1, BoHV-5, OvHV-2 e SuHV-1 em amostras de tecidos

\begin{tabular}{|c|c|c|c|c|c|c|}
\hline Iniciador & Sequência & $\begin{array}{l}\text { Amplicom } \\
(\mathrm{pb})\end{array}$ & Vírus & Alvo & $\begin{array}{l}\text { Acesso* } \\
\text { GenBank }\end{array}$ & Posição \\
\hline $\begin{array}{l}\text { BoHV- } \\
191-F\end{array}$ & TCTTTACGGTCGACGACTCC & 191 & $\begin{array}{l}\text { BoHV-1 } \\
\text { BoHV-5 }\end{array}$ & $\mathrm{gC}$ & AJ004801.1 & $\begin{array}{l}17061- \\
17078\end{array}$ \\
\hline $\begin{array}{l}\text { BoHV- } \\
191-\mathrm{R}\end{array}$ & GAAGTACACGCGCAGCTC & & & & & $\begin{array}{l}17232- \\
17251\end{array}$ \\
\hline $\begin{array}{l}\text { OvHV2- } \\
102-\mathrm{F}\end{array}$ & CAACGTCGGTGACACCATCGA & 102 & OvHV-2 & $\mathrm{gB}$ & AY839756.1 & $\begin{array}{l}18820- \\
18840\end{array}$ \\
\hline $\begin{array}{l}\text { OvHV2- } \\
102-\mathrm{R}\end{array}$ & TCTCGGAGCACAGACACGGTT & & & & & $\begin{array}{l}18901- \\
18921\end{array}$ \\
\hline $\begin{array}{l}\text { SuHV1- } \\
499-F\end{array}$ & CCGCGGGCCGTGTTCTTTGT & 499 & SuHV-1 & $\mathrm{gE}$ & ВK001744.1 & $\begin{array}{l}124093- \\
124112\end{array}$ \\
\hline $\begin{array}{l}\text { SuHV1- } \\
499-\mathrm{R}\end{array}$ & CGTGGCCGTTGTGGGTCAT & & & & & $\begin{array}{l}124567- \\
124585\end{array}$ \\
\hline
\end{tabular}

*Número de acesso relativo ao genoma completo de cada herpesvírus. 
A opção de diferenciar BoHV-1 de BoHV-5 por restrição enzimática deve-se ao fato de o BoHV1 também causar danos neurológicos (Rissi et al., 2008). Como a presença de um par extra de iniciadores poderia diminuir a eficiência da PCR, optou-se por diferenciar os dois herpesvírus bovinos por restrição enzimática. A análise in silico de restrição enzimática foi realizada no programa pDraw 32 (Tipman, 2004).

A PCR foi otimizada variando-se a concentração dos reagentes e o tipo de DNA polimerase. Foram testadas uma DNA polimerase convencional $\left(\right.$ GoTaq $^{\circledR}$ DNA Polymerase, Promega, EUA) e duas DNA polimerase do tipo hotstart (Platinum ${ }^{\circledR}$ Taq DNA PolymeraseInvitrogen, EUA e JumpStart ${ }^{\circledR}$ Taq DNA Polymerase- Sigma, EUA). A concentração do DNA nas reações variou de 20 a $150 \mathrm{ng} / \mu \mathrm{L}$.

A reação foi padronizada com as seguintes concentrações dos reagentes, para um volume final de reação de $25 \mu \mathrm{L}$ : 10 pmol dos iniciadores OvHV2-102, 20pmol dos iniciadores BoHV-191 e, 5pmol dos iniciadores SuHV1-499 (IDT, EUA), $2 \mathrm{mM}$ de $\mathrm{MgCl}_{2}, 3 \%$ DMSO, 200mM de DNTP, 2 U DNA polimerase (Platinum ${ }^{\circledR}$ Taq DNA Polymerase, Invitrogen, EUA), Tampão 5x GoTaq $^{\circledR}$ Green (Promega, EUA). O termociclador foi programado com: um ciclo de desnaturação a $95^{\circ} \mathrm{C}$ por $4 \mathrm{~min}, 35$ ciclos a $95^{\circ} \mathrm{C}$ por $40 \mathrm{~s}, 62^{\circ} \mathrm{C}$ por $40 \mathrm{~s}, 72^{\circ} \mathrm{C}$ por $40 \mathrm{~s}$ e um ciclo final de extensão de $72^{\circ} \mathrm{C}$ por 5 min. As amostras de referência mencionadas anteriormente foram utilizadas como controles positivos para todas as reações realizadas. Além delas, foi utilizado como controle negativo tecido encefálico bovino e, como controle branco, água destilada. Os resultados foram visualizados em gel de agarose a $2,5 \%$, corado com brometo de etídeo sob luz ultravioleta, após eletroforese.

Cada par de iniciadores foi testado individualmente com os quatro vírus para se verificar a presença de amplificações inespecíficas. A especificidade da reação também foi testada em sete isolados brasileiros de SuHV-1 previamente caracterizados (Fonseca Jr. et al., 2010a), cinco isolados de BoHV-1, Streptococcus suis, Listeria monocytogenes. O DNA de todas essas amostras foi extraído segundo Fonseca Jr. et al. (2010b).

O teste de sensibilidade analítica foi realizado apenas para BoHV-1, BoHV-5 e SuHV-1, uma vez que o OHV-2 não é cultivado em linhagem celular. Isolados desses vírus foram titulados em célula de linhagem MDBK (rins de bovino). A solução estoque desses vírus foi diluída sucessivamente em base 10 e submetida à extração de DNA. O DNA foi estocado a $-20^{\circ} \mathrm{C}$ até o momento do uso. A sensibilidade foi testada com os iniciadores separados (PCR) e em conjunto na mPCR. A segunda etapa dos testes de sensibilidade foi realizada por meio da infecção de amostras do encéfalo de bovinos negativos para os três vírus e sem sinais clínicos de encefalite. Vírus titulado e novamente diluído na base dez foi adicionado ao tecido animal antes da extração do DNA.

Um sistema semelhante foi utilizado para a determinação da sensibilidade analítica do OvHV-2, porém com a utilização de produtos de PCR com concentrações estimadas em um equipamento Nanovue $\AA$ (GE Healthcare, Estados Unidos).

\section{RESULTADOS}

A mPCR apresentou bandas específicas para cada agente pesquisado (Fig. 1). Os fragmentos amplificados para os herpesvírus bovinos puderam ser diferenciados por restrição enzimática (Fig. 2). Após análise in silico, a enzima BtgI foi escolhida para diferenciação dos resultados por clivar o amplicom de BoHV-5 em dois fragmentos (139pb e 52pb) e não clivar o amplicom de BoHV-1. A reação foi realizada segundo recomendação do fabricante (New England Biolabs ${ }^{\circledR}$ ). 


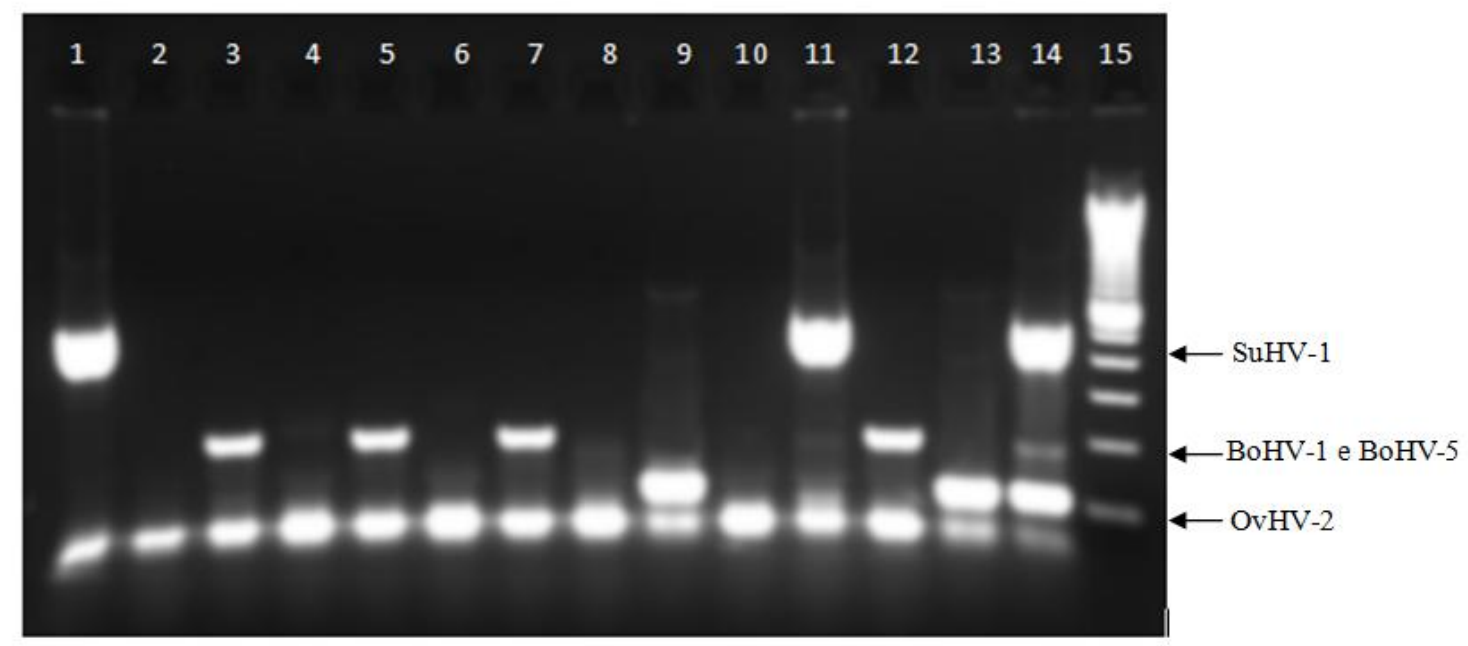

Figura 1. Eletroforese em gel de agarose $2 \%$ da mPCR. Os resultados dos controles positivos e 10 amostras clínicas foram agrupados para visualização. 1 - amostra de encéfalo de suíno positiva para SuHV-1; 2 - amostra de encéfalo de suíno negativa; 3 - amostra de encéfalo de bovino positiva para BoHV; 4 - amostra de encéfalo de bovino negativa; 5 - amostra de encéfalo de bovino positiva para BoHV; 6 - amostra de encéfalo de bovino negativa; 7 - amostra de encéfalo de bovino positiva para BoHV; 8 - amostra de encéfalo de bovino negativa; 9 - amostra de encéfalo de ovino positiva para OvHV-2; 10 - amostra de encéfalo de ovino negativa; 11 - controle positivo de SuHV-1; 12 - controle positivo de BoHV-1; 13 - controle positivo de OvHV-2; 14 - controle positivo com DNA de BoHV-1, OVHV-2 e SuHV-2; 15 - padrão de tamanho molecular com intervalo de 100 pares de base entre as bandas (banda inicial com 100 pares de base).

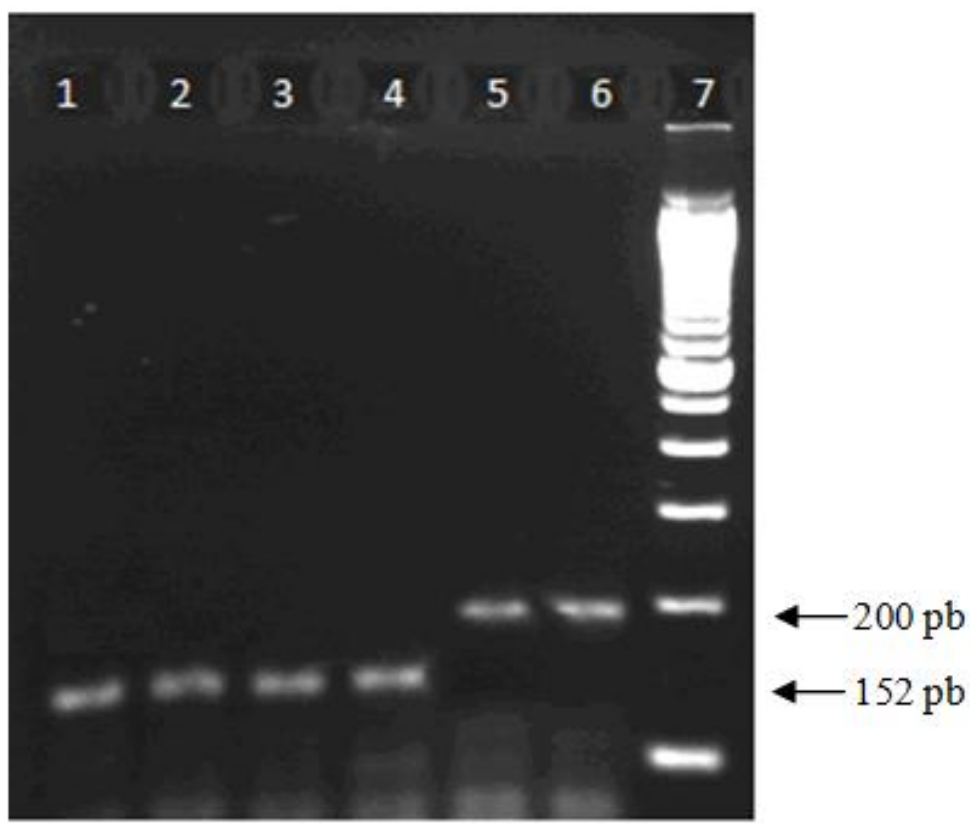

Figura 2. Eletroforese em gel de agarose $2 \%$ da mPCR de resultados positivos para BoHV-1 e BoHV-5 digeridos pela enzima de restrição BtgI. 1 - controle positivo de BoHV-5; 2 a 4 - amostra clínica de BoHV-5; 5 - amostra clínica de BoHV-1; 6 - controle positivo de BoHV-1; 7 - padrão de tamanho molecular com intervalo de 100 pares de base entre as bandas (banda inicial com 100 pares de base). 
Os iniciadores amplificaram especificamente todos os isolados de SuHV-1 e BoHV-1, sem apresentarem bandas inespecíficas quando o DNA $S$. suis ou $L$. monocytogenes foi adicionado. Não houve amplificação inespecífica na PCR com os iniciadores isolados (dado não mostrado).

A sensibilidade analítica para detecção de BoHV-1, BoHV-5 e SuHV-1 foi, respectivamente, $10^{1,2} \quad \mathrm{TCID}_{50} / \mathrm{mL}, \quad 10^{1,0}$ $\mathrm{TCID}_{50} / \mathrm{mL}, \quad 10^{1,3} \mathrm{TCID}_{50} / \mathrm{mL}$ na reação multiplex. Os resultados foram semelhantes para a PCR realizada com os primers separadamente e com tecido bovino contaminado com o vírus titulado. Na detecção de OvHV-2, a reação apresentou sensibilidade de 300 cópias $/ \mu \mathrm{L}$ com o DNA puro do agente, porém houve redução para $3000 / \mu \mathrm{L}$ cópias ao se utilizar o material contaminado (Fig. 3).

Os resultados da mPCR aplicada às amostras clínicas testadas nesse trabalho estão especificados na Tab. 2.

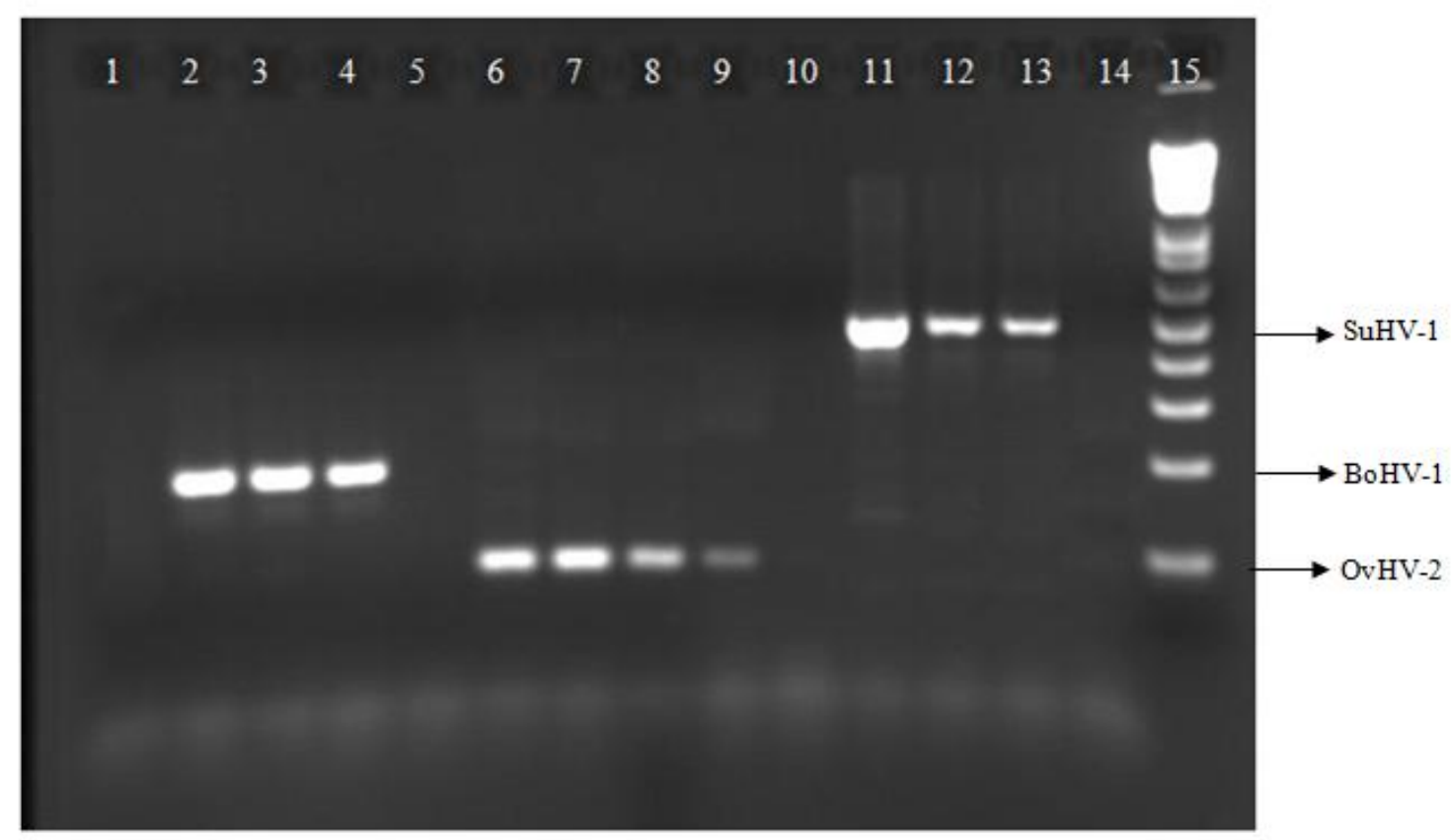

Figura 3. Sensibilidade analítica da mPCR realizada com amostras de encéfalo bovino contaminadas com DNA viral extraído a partir de suspensão viral titulada ou produtos de PCR quantificados. 1 - controle negativo (amostra de cérebro de bovino); 2 - BoHV-1 $10^{4,3}$ TCID $_{50} / \mathrm{mL} ; 3$ - BoHV-1 $10^{3,3}$ TCID $_{50} / \mathrm{mL} ; 4$

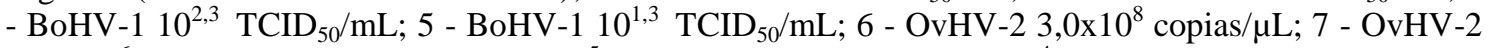

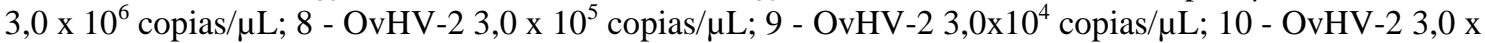
$10^{3}$ copias/ $\mu \mathrm{L} ; 11$ - SuHV-1 10 $10^{2,0}$ TCID $_{50} / \mathrm{mL} ; 12$ - SuHV-1 $10^{1,0}$ TCID $_{50} / \mathrm{mL} ; 13$ - SuHV-1 $10^{0,0}$ TCID $_{50} / \mathrm{mL} ; 14$ - branco; 15 - padrão de tamanho molecular com intervalo de 100 pares de base entre as bandas (banda inicial com 100 pares de base).

Tabela 2. Resultados obtidos na mPCR desenvolvida para detecção de BoHV-1, BoHV-5, OvHV-2, SuHV-1 a partir de amostras clínicas

\begin{tabular}{|c|c|c|c|c|c|c|}
\hline \multirow{2}{*}{ Amostra } & \multirow{2}{*}{ Total } & \multicolumn{4}{|c|}{ Positiva } & \multirow{2}{*}{ Negativa } \\
\hline & & BoHV-1 & BoHV-5 & OvHV-2 & SuHV-1 & \\
\hline Encéfalo bovino & 65 & 1 & 10 & 5 & 0 & 49 \\
\hline Encéfalo suíno & 35 & 0 & 0 & 0 & 25 & 10 \\
\hline Encéfalo ovino & 4 & 0 & 0 & 3 & 0 & 1 \\
\hline Sêmen ovino & 10 & 0 & 0 & 6 & 0 & 4 \\
\hline
\end{tabular}




\section{DISCUSSÃO}

A mPCR padronizada neste trabalho foi capaz de detectar e diferenciar quatro tipos de vírus causadores de encefalite em bovinos e de sinais neurológicos em outras espécies, como ovinos e suínos. Todos esses agentes são listados no Manual da OIE (Manual..., 2008), sendo considerados, portanto, de elevada importância na pecuária internacional. Sua importância se estende em diversas áreas, sendo que pelo menos dois deles, OvHV-2 e SuHV-1, podem infectar diversas espécies.

O diagnóstico diferencial é importante para determinar as medidas sanitárias a serem tomadas. A encefalite causada por SuHV-1, por exemplo, é sinal de que existem suínos infectados na área, pois esses são os principais reservatórios deste vírus (Fonseca Jr. et al., 2010c). A pseudorraiva, doença causada pelo SuHV-1, é uma enfermidade de notificação obrigatória e de grande impacto na cadeia produtiva de suínos.

A mPCR descrita neste trabalho foi padronizada analisando-se variáveis como concentração de magnésio, DNA polimerase, iniciadores, além da temperatura de anelamento. As reações em multiplex são muito mais sensíveis às variações do que aquelas realizadas com apenas um par de iniciadores. É preciso considerar diversas variáveis, pois até mesmo iniciadores idênticos podem ter desempenho diferente em diferentes laboratórios (Bastien et al., 2008). O tipo e o fabricante da enzima DNA polimerase utilizada geraram variações na sensibilidade e especificidade da reação, sendo a mais eficiente a enzima do tipo hotstart. Essa enzima só é ativada após o primeira etapa de desnaturação, o que diminui o número de interação inespecífica e formação de dímeros dos iniciadores. Dentre outros reagentes testados, a utilização de um tampão diferente do normalmente usado para a Platinum ${ }^{\circledR}$ Taq DNA Polymerase e de DMSO foi relevante, sendo esse último importante para evitar a inibição da atividade de polimerização devido às estruturas secundárias, algo muito comum em genomas com alto índice de guanina e citosina como o da família Herpesviridae (Hengen, 1997).
Cerca de $15 \%$ das amostras analisadas nesse trabalho foram positivas para BoHV-5. Outros artigos relatam entre $11 \%$ (Rissi et al., 2010) e $27 \%$ (Pinto et al., 2003). Esses dados indicam que a incidência desse herpesvírus pode ser bastante variável conforme a região analisada. Existe a possibilidade de que os resultados positivos para BoHV-5 e BoHV-1 em encéfalo bovino sejam provenientes de vírus latentes, como alertado por Campos et al. (2009). Como não foi realizado o isolamento do vírus, foi possível comprovar apenas a presença do DNA viral nessas amostras.

Os resultados para a presença de OvHV-2 em encéfalo bovino são semelhantes aos descritos por Rissi et al. (2010), cujos trabalhos encontraram cerca de $4,2 \%$ de amostras positivas. Cerca de $7,6 \%$ dos tecidos submetidos à mPCR nesse trabalho foram positivos para OvHV-2. A incidência de latência desse vírus em bovinos é baixa. Geralmente a enfermidade tem curso fatal, o que indica que os sinais nervosos dos animais positivos na PCR ocorreram devido à infecção pelo OvHV-2.

Todas as amostras de encéfalo bovino utilizadas neste trabalho provinham de animais com sinais nervosos, no entanto a maior parte delas foi negativa para os três herpesvírus. É preciso salientar que diversos outros microrganismos causam encefalite com sinais semelhantes aos da raiva, como a leucose enzoótica bovina, listeriose, enterotoxemia e a forma cerebral da babesiose, assim como intoxicação por plantas tóxicas ou chumbo (Riet-Correa et al., 1998; Claus et al., 2002). Os sinais neurológicos manifestados pelos animais dos quais as amostras negativas eram provenientes podem, portanto, ser decorrentes da presença de outros agentes ou de outras alterações no sistema nervoso central desses animais.

Gunson et al. (2008) relataram a importância das reações de PCR multiplex na rotina do laboratório. Uma reação bem padronizada aumenta a velocidade do trabalho e otimiza a utilização dos termocicladores e o preparo das reações de PCR. O método pode ser utilizado até mesmo quando apenas dois dos agentes são suspeitos de provocar a doença, como no caso do SuHV-1 e do OvHV-2, que podem causar sinais neurológicos em suínos (Albini et al., 2003). 


\section{CONCLUSÕES}

Os estudos permitiram desenvolver uma PCR multiplex capaz de detectar quatro agentes infecciosos relacionados a encefalites bovinas. Além da praticidade de seu uso no diagnóstico diferencial de doenças do sistema nervoso bovino, essa técnica pode ser utilizada na para detecção desses mesmos agentes em tecidos suínos e ovinos.

\section{AGRADECIMENTOS}

Esse trabalho teve o apoio financeiro do INCT de Informação Genético-sanitária da Pecuária Brasileira (CNPq 573899/2008-8) e do Ministério da Agricultura, Pecuária e Abastecimento. Os autores agradecem ao professor Paulo Roehe, pela doação do isolado de BoHV-5.

\section{REFERÊNCIAS BIBLIOGRÁFICAS}

ALBINI, S.; ZIMMERMANN, W.; NEFF, F. et al. Porcine malignant catarrhal fever: diagnostic findings and first detection of the pathogenic agent in diseased swine in Switzerland. Schweiz. Arch. Tierheilkd., v.145, p.61-68, 2003.

ALTSCHUL, S.F; GISH. W.; MILLER, W. et al. Basic local alignment search tool. J. Mol Biol., v.215, p.. 403-410, 1990.

ARRUDA, L.P.; NAKAZATO, L.; DUTRA, V. et al. Detecção molecular de herpesvírus bovino 1 e 5 em amostras de encéfalo conservadas em formol e emblocadas em parafina provenientes de bovinos com doença neurológica. Pesqui. Vet. Bras., v.30, p.646650, 2010.

BASTIEN， P.; PROCOP， G.W.; REISCHL，U. Quantitative real-time PCR is not more sensitive than "conventional" PCR. J. Clin. Microbiol., v.46, p.18971900, 2008.

BATISTA, H.B.C.R.; SCHMIDT, E.; SPILKI, F.R. et al. Herpesvírus bovinos (BoHV-1.1 e BoHV-1.2b) em forma infecciosa em encéfalos de bovinos submetidos ao diagnóstico de raiva no estado do Rio Grande do Sul. Arq. Bras. Med. Vet. Zootec., v.62, p.1023-1028, 2010

BRAGA, A.C.; ROSA, J.C.; ROEHE, P.M. et al. Diagnóstico da doença de Aujeszky em suínos no estado do Rio Grande do Sul. Vet. Foco, v.2, p.177$182,2005$.

BOOM, R.; SOL, C.J.A.; SALIMANS, M.M.M. et al. Rapid and simple method for purification of nucleic acids. J. Clin. Micol., v.28, p.495-503, 1990.
BROWER, A.; HOMB, K.M.; BOCHSLER, P. et al. Encephalitis in aborted bovine fetuses associated with Bovine herpesvirus 1 infection. J. Vet. Diagn. Invest., v.20, p.297-303, 2008.

CAMPOS, F.S.; FRANCO, A.C.; HÜBNER, S.O. et al. High prevalence of co-infections with bovine herpesvirus 1 and 5 found in cattle in southern Brazil. Vet. Microbiol., v.139, p.67-73, 2009.

CLAUS, M.P.; ALFIERI, A.F.; ALFIERI, A.A. Herpesvírus bovino tipo 5 e meningoencefalite herpética bovina 1 Meningoencephalitis by Herpesvirus Type 5. Semina: Cienc. Agrar., v.23, p.131-141, 2002.

COSTA, E.A. Diagnóstico das encefalites herpéticas em bovinos. 2007. 57f. Tese (Doutorado em Ciência Animal) - Escola de Veterinária, Universidade Federal de Minas Gerais, Belo Horizonte, MG.

COSTA, E.A.; BOMFIM, M.R.; DA FONSECA, F.G. et al. Ovine herpesvirus 2 infection in foal, Brazil. Emerg. Infect. Dis., v.15, p.844-845, 2009.

DAVISON, A.J.; EBERLE, R.; EHLERS, B. et al. The order herpesvirales. Arch. Virol., v.154, p.171$177,2009$.

DEL MÉDICO, M.P.; LADELFA, M.F.; KOTSIAS, F. et al. Biology of bovine herpesvirus 5. Vet. J., v.184, p.138-145, 2010.

ESTEVES, P.A.; DELlagOSTIN, O.A.; PINTO, L.S. et al. Phylogenetic comparison of the carboxyterminal region of glycoprotein $\mathrm{C}(\mathrm{gC})$ of bovine herpesviruses (BoHV) 1.1, 1.2 and 5 from South America (SA). Virus Res., v.131, p.16-22, 2008.

FONSECA Jr., A.A.; CAMARGOS, M.F.; CIACCIZANELLA, J.R. et al. Diagnóstico e genotipagem do vírus da pseudorraiva por nested-PCR e análise de restrição enzimática. Cienc. Rural, v.40, p.921-927, 2010a.

FONSECA Jr., A.A.; CAMARGOS, M.F.; DE OLIVEIRA, A.M. et al. Molecular epidemiology of Brazilian pseudorabies viral isolates. Vet. Microbiol., v.141, p.238-245, 2010b.

FONSECA Jr., A.A.; LEITE, R.C.; HEINEMANN, M.B.; REIS, J.K.P. A comparative analysis of envelope and tegument proteins of suid herpesvirus 1, bovine herpesvirus 1 and bovine herpesvirus 5. Arch. Virol., v. 155, p. 1687-1692, 2010c.

GAILBREATH, K.L.; TAUS, N.S.; CUNHA, C.W. et al. Experimental infection of rabbits with ovine herpesvirus 2 from sheep nasal secretions. Vet. Microbiol., v.132, p.65-73, 2008. 
GARMATZ, S.L.; IRIGOYEN, L.F.; RECH, R.R. et al. Febre catarral em bovinos no Rio Grande do Sul : transmissão experimental para bovinos e caracterização do agente etiológico. Pesq. Vet. Bras., v.24, p.93-106, 2004.

GUNSON, R.N.; BENNETT, S.; MacLEAN, A.; CARMAN, W.F. Using multiplex real time PCR in order to streamline a routine diagnostic service. $J$. Clin. Virol., v.43, p.372-375, 2008.

HENGEN, P.N. Optimizing multiplex and LA-PCR with betaine. Trends Biochem. Sci., v.22, p.225-226, 1997.

HALL, T.A. BioEdit: a user-friendly biological sequence alignment editor and analysis program for Windows 95/98/NT. Nucl. Acids. Symp. Ser., v.41, p.95-98, 1999.

KIBBE, W.A. OligoCalc: an online oligonucleotide properties calculator. Nucleic Acids Res., v.35, W4346, 2007.

LI, H.; GAILBREATH, K.; FLACH, E.J. et al. A novel subgroup of rhadinoviruses in ruminants. $J$. Gen. Virol., v.86, p.3021-3026, 2005.

MANUAL of diagnostic tests and vaccines for terrestrial animals. Paris: OIE, 2008. 1343p.

MUYLKENS, B.; THIRY, J.; KIRTEN, P.; et al. Bovine herpesvirus 1 infection and infectious bovine rhinotracheitis. Vet. Res., v. 38, p. 181-209, 2007.

PINTO, A.M.V.; ROMIJN, P.C.; SILVA, R.C.F. et al. Geographic distribution of BHV-5 in Rio de Janeiro state. In: NATIONAL MEETING OF VIROLOGY, 14., 2003, Florianópolis. Anais... São Paulo, SP: Sociedade Brasileira de Virologia, 2003. p.141.

POMERANZ, L.E.; REYNOLDS, A.E.; HENGARTNER, C.J. Molecular biology of pseudorabies virus: impact on neurovirology and veterinary medicine. Microbiol. Mol. Biol. Rev., v.69, p.462-500, 2005.
RIET-CORREA, F.; SCHILD, A.L.; FERNANDES, C.G. Enfermidades do sistema nervoso dos ruminantes no sul do Rio Grande do Sul. Cienc. Rural, v.28, p.341-348, 1998.

RISSI, D.R.; RECH, R..R.; FLORES, E.F. et al. Meningoencefalite por herpesvírus bovino-5. Pesq. Vet. Bras., v.27, p.251-260, 2007.

RISSI, D.R.; PIEREZAN, F.E.; SILVA, M.S. et al. Neurological disease in cattle in southern Brazil associated with Bovine herpesvirus infection. J. Vet. Diagn. Invest., v.20, p.346-349, 2008.

RISSI, D. R.; PIEREZAN, F.; OLIVEIRA-FILHO, J.C. et al. Abordagem diagnóstica das principais doenças do sistema nervoso de ruminantes e equinos no Brasil. Pesq. Vet. Bras. v.30, p.958-967, 2010.

RUSSELL， G.C.; STEWART, J.P.; HAIG， D.M. Malignant catarrhal fever: a review. Vet. J., v.179, p.324-335, 2009.

THIRY, J.; KEUSER, V.; MUYLKENS, B. et al. Ruminant alphaherpesviruses related to bovine herpesvirus 1. Vet. Res. v.37, p.169-190, 2006.

TIPPMANN, H.F. Analysis for free: comparing programs for sequence analysis. Brief Bioinform., v.5, p.82-87, 2004.

UNTERGASSER, A.; NIJVEEN, H.; RAO, X. et al. Primer3Plus, an enhanced web interface to Primer3. Nucleic Acids Res., v.35, W71-W74, 2007.

YEH, H.Y.; YATES, M.V.; CHEN, W. et al. Realtime molecular methods to detect infectious viruses. Semin. Cell Dev. Biol., v.20, p.49-54, 2009. 